РАСШИРЕНИЕ КЛИМАТИЧЕСКОГО НОЗОАРЕАЛА КРЫМСКОЙ ГЕМОРРАГИЧЕСКОЙ ЛИХОРАДКИ НА ТЕРРИТОРИИ РОССИИ И СОСЕДНИХ СТРАН В УСЛОВИЯХ ПРЕДПОЛАГАЕМОГО ИЗМЕНЕНИЯ КЛИМАТА

\author{
В.В. Ясюкевич*, И.О.Попов**
}

\begin{abstract}
Институт глобального климата и экологии имени академика Ю. А. Израэля, РФ, 107258, г. Москва, ул. Глебовская, д. 20Б,

*адрес для переписки: v1959@yandex.ru; igor_o_popov@mail.ru
\end{abstract}

Реферат. Цель работы - дать краткую характеристику Крымской геморрагической лихорадки (КГЛ) (альтернативное название - геморрагическая лихорадка Крым-Конго) как нозологической единицы и дать прогноз возможных климатообусловленных изменений нозоареала на территории России и соседних стран в связи с прогнозируемым изменением климата в соответствии со сценариями умеренного и экстремального антропогенного воздействия на климатическую систему Земли RCP4.5 и RCP8.5. Крымская геморрагическая лихорадка (КГЛ) - острое инфекционное заболевание человека, передающееся через укусы клещей аридной зоны. Заболеваемость на территории Российской Федерации невелика, не более 300 случаев в год (по многолетним данным). Однако у людей эта болезнь часто сопровождается тяжелым течением, поражением многих органов и систем больного. Для моделирования нозоареала КГЛ был использован климатический предиктор: изотерма суммы активных температур (САТ) $3000^{\circ} \mathrm{C} \cdot$ сут при пороговом значении $10^{\circ} \mathrm{C}$, которая вполне удовлетворительно совпадает с северной границей нозоареала КГЛ, приведенной в специальной научной литературе. Помимо климатических ограничений, нами было введено в модель и биоценологическое: северная граница нозоареала совпадает с северной границей лесостепи, так как переносчики - клещи аридной зоны. Модельные картографические оценки изменений нозоареала КГЛ в соответствии со сценарием умеренного антропогенного воздействия на климатическую систему Земли RCP4.5 показали, что нозоареал КГЛ на территории России и соседних стран в течение XXI века будет расширяться в северном направлении, а также в высокогорные районы Кавказа и Центральной Азии. Особенности изменения нозоареала КГЛ в соответствии со сценарием RCP8.5 те же, но расширение нозоареала более выражено. Эти изменения наиболее полно будут реализовываться в том случае, если границы аридных зон несколько сдвинутся к северу за счет смещения южной границы лесной зоны. Оценки изменений в соответствии с обоими сценариями не выявили тенденции к сокращению нозоареала в России и соседних странах.

Ключевые слова. Изменение климата, климатические сценарии, крымская геморрагическая лихорадка, моделирование ареалов, климатические сценарии, клещи аридной зоны. 


\section{Введение}

Инфекционные болезни человека, в том числе и трансмиссивные, распространены практически повсеместно. Большинство их является климатозависимыми. Изменение климата приводит к изменению условий их распространения. Для трансмиссивных заболеваний меняются условия существования переносчиков, условия развития возбудителей в переносчике, а также условия существования различных позвоночных животных, которые в случае природно-очаговых заболеваний являются резервуарами инфекции. Для нетрансмиссивных заболеваний изменения климата имеют значение для области распространения животных, являющихся резервуарами инфекции.

При этом необходимо дифференцировать изменения, вызванные климатическими факторами, от изменений, обусловленных другими факторами. Первые происходят на фоне действия различных факторов неклиматической природы - экологических, демографических и социально-экономических. Характер их действия на территории России в последние десятилетия существенно изменился. Например, заболеваемость клещевым энцефалитом зависит от объемов вакцинации, от подавления очагов методами неспецифической профилактики, от происходящего увеличения частоты контактов населения, в первую очередь, городского с возбудителями и переносчиками на садово-огородных участках. В значительной степени данная проблема может быть решена посредством применения методов математического моделирования в экологических и биогеографических исследованиях (Попова, Попов, 2019). Для России изучения влияния климата и его изменений на динамику заболеваемости и оценка климатообусловленных изменений распространения возбудителей заболеваний и их переносчиков особенно актуальны, так как изменение климата на ее территории происходит более интенсивно, чем в глобальном масштабе (Оценочный доклад..., 2008, Второй оценочный доклад Росгидромета..., 2014).

Крымская геморрагическая лихорадка (КГЛ) периодически регистрируется в Южном и Северокавказском федеральных округах Российской Федерации. Кроме территории России, заболевание отмечается в Центральной Азии, Китае, Украине, Болгарии, на территории бывшей Югославии, в Пакистане, Казахстане и Средней Азии, Центральной, Восточной и Южной Африке (Конго, Кения, Уганда, Нигерия и др.).

Возбудителем этого заболевания является вирус из семейства Buyaviridae, род Nairovirus, способный репродуцироваться в двух температурных интервалах: $36-40^{\circ} \mathrm{C}$ и $22-25^{\circ} \mathrm{C}$. Это позволяет вирусу размножаться как в организме человека и позвоночных животных, так и в организме кровососущих членистоногих. Переносчиками вируса в природе являются клещи аридной зоны рода Hyalomma. В Европейской части России важнейшие из них $-H$. marginanum, в Средней Азии - H. anatolicum. Вирус выделен также и из некоторых других видов клещей (иксодовых $H$. plumbeum plumbeum, $H$. anatolicum, H. asiaticum, H. detritum; Rhipicephalus rossicus, Rh. bursa, Rh. sanguineus, Rh. pumilio; Dermacentor marginatus, D. daghestanicus; Boophilus 
calcaratus и аргасового - Argas persicus), характерных для лесостепных, степных и полупустынных биотопов. В организме клещей вирус сохраняется длительное время и передается трансовариально и трансфазово.

Резервуарами инфекции служат дикие (грызуны, зайцы, ежи) и домашние (крупный рогатый скот, верблюды) млекопитающие, а также птицы. Основной путь передачи инфекции трансмиссивный, но возможен и контактный (контаминантный), например, при раздавливании клеща. Явные признаки заболевания у животных отсутствуют. У людей часто сопровождается тяжелым течением болезни, поражением многих органов и систем больного. Летальность может достигать 10-40\% (Руководство по зоонозам, 1983; Львов и др., 1989; Тарасов, 2002; Конго-крымская геморрагическая лихорадка, 2013).

Целью настоящей работы является оценка возможных изменений климатообусловленного нозоареала Крымской геморрагической лихорадки (КГЛ) в условиях изменяющегося климата. Отправной точкой послужила работа С. Е. Смирновой (2006), где приводится глобальный анализ распространения КГЛ. Автор приходит к выводу, что северная граница нозоареала этого заболевания проходит в Евразии по линии Венгрия - Донецкая область - Астраханская область - озеро Балхаш по изотерме суммы эффективных температур $3000^{\circ} \mathrm{C} \cdot$ сут при пороговом значении $10^{\circ} \mathrm{C}^{1)}$. Согласно нашим оценкам (Попова и др., 2019) зона со значениями СЭТ более $3000^{\circ} \mathrm{C} \cdot$ сут при пороговом значении $10^{\circ} \mathrm{C}$ расположена только в южной части Республики Туркменистан по границе с Ираном и Афганистаном и не соответствует приведенному в статье рисунку. Однако, изотерма САТ $3000^{\circ} \mathrm{C} \cdot$ сут при пороге $10^{\circ} \mathrm{C}$ вполне удовлетворительно совпадает с северной границей нозоареала КГЛ, приведенной в цитируемой статье. Это значение предиктора распространения и было принято в наших модельных расчетах.

\section{Материалы и методы}

Исходная метеорологическая информация и методика построения карт аналогична ранее опубликованной нами в статье (Ясюкевич и др., 2019).

Оценка предполагаемых изменений нозоареала КГЛ на протяжении XXI века основывается на климатических обобщениях, выполненных Главной геофизической обсерватории им. А. И. Воейкова (ГГО) по параметрам будущего климата. Они получены осреднением результатов вычислений по ансамблю из 31 МОЦАО (Моделей Общей Циркуляции Атмосферы и Океана), которые участвовали в проекте CMIP5 (Coupled Model Intercomparison Project - Phase 5). В этих расчетах использовались современные сценарии антропогенного воздействия на климатическую систему Земли семейства RCP (Representative

1) СЭТ - сумма эффективных температур с заданным пороговым значением есть сумма за год превышений среднесуточной температурой этого порового значения.

САТ - сумма активных температур с заданным пороговым значением есть сумма за год среднесуточных температур, превышающих это пороговое значение. 
Concentration Pathways): сценарий умеренного воздействия RCP4.5 и сценарий экстремального воздействия RCP8.5, подробно представленные в разделе 3 Второго оценочного доклада..., 2014.

Основные климатические характеристики, рассчитанные в соответствии со сценариями RCP4.5 и RCP8.5, для периодов 2011-2030 гг. и 2034-2053 гг. для RCP4.5 или 2028-2047 гг. для RCP8.5 практически одинаковы. Различия проявляются в период 2041-2060 гг. и достигают максимума в период 2080-2099 гг. Точки на оси абсцисс соответствуют центрам указанных двадцатилетних периодов. Изменение климатических характеричтик с указанные периоды показано на (рис. 1). Значения по оси ординат - двадцатилетнее скользящее среднее. Пространственное осреднение проводилось по территории России и стран ближнего зарубежья.

Практически это приводит к тому, что визуально картосхемы за периоды 2011-2030 гг. и 2034-2053 гг. для RCP4.5 и 2028-2047 гг. для RCP8.5, отличаются лишь мелкими деталями. Поэтому картосхемы за эти периоды для сценария RCP8.5 в тексте мы приводить не будем, хотя они были построены и проанализированы.

Помимо климатических ограничений нами было введено в модель и биоценологическое - северная граница лесостепи, так как переносчиками возбудителя КГЛ являются клещи аридной зоны.

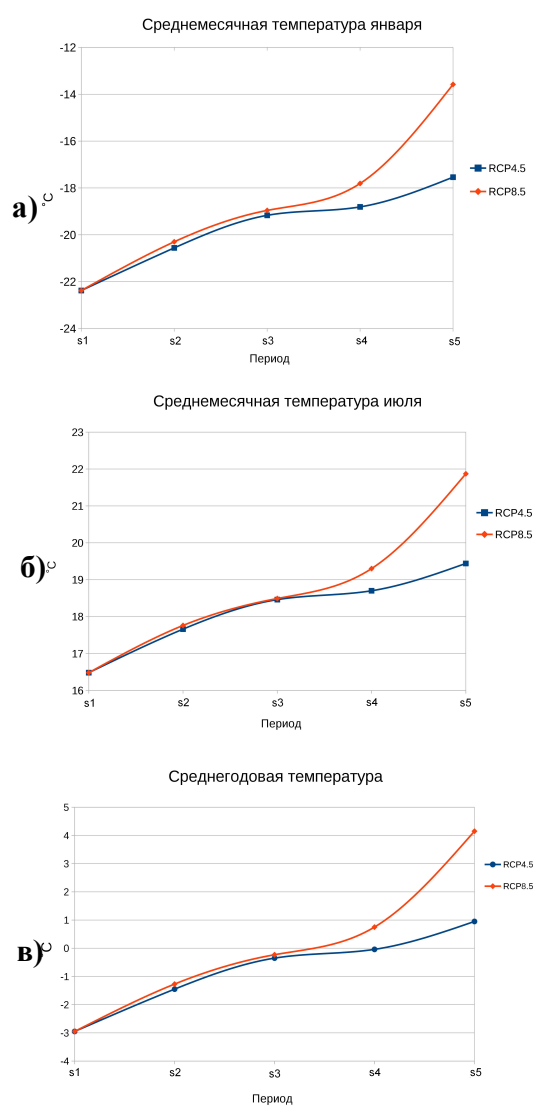




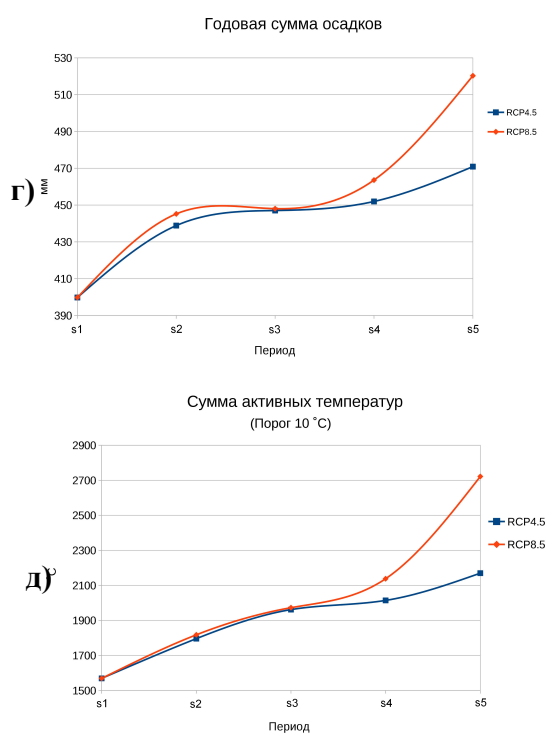

Рисунок 1. Ожидаемые изменения климатических параметров в течение XXI века, соответствующие изменениям среднемодельного климата для ансамбля из 31 модели общей циркуляции атмосферы и океана семейства СМIP5 на территории России и соседних стран при двух сценариях антропогенного воздействия на климатическую систему Земли - RCP4.5 и RCP8.5:

a) среднемесячная температура января, б) среднемесячная температура июля,

в) среднегодовая температура, г) годовая сумма осадков, д) сумма активных температур (Попов, 2016)

Figure 1. Projected changes of climate parameters in the 21 st century corresponding to changes in the average multi-model climate for the ensemble of 31 General Circulation Models of the Atmosphere and Ocean of CMIP5 family in Russia and neighboring countries under two scenarios of anthropogenic impact on the Earth's climate system, RCP4.5 and RCP8.5: a) monthly mean January temperature, b) monthly mean July temperature, c) annual mean temperature, d) yearly precipitation total, d) the sum of active temperatures (Popov, 2016)

\section{Результаты и обсуждение}

На рис. 2 представлена многолетняя динамика заболеваемости КГЛ. Как видно, пиковыми по заболеваемости были 2006-2008 гг. Некоторый подъем заболеваемости отмечен в 2016 г. Затем произошло снижение заболеваемости и подъем в 2019 г.

Имеющиеся региональные данные по заболеваемости КГЛ свидетельствуют о том, что наиболее уязвимо в отношении этого заболевания население Ставропольского края, Республики Калмыкия, Астраханской и Ростовской областей. Число обращений по поводу укуса клеща в Южном и Северокавказском ФО сравнительно невелико - в последние годы колеблется между 20-25 тыс. против 400-500 тыс. в лесной зоне РФ (Руководство по зоонозам. 1983. Ясюкевич и др., 2016; О санитарно-эпидемиологической обстановке в Российской Федерации... 2002-2011; О состоянии санитарноэпидемиологического благополучия населения..., 2012-2019; Инфекционная заболеваемость в Российской Федерации за январь-декабрь, 2018 г.). 


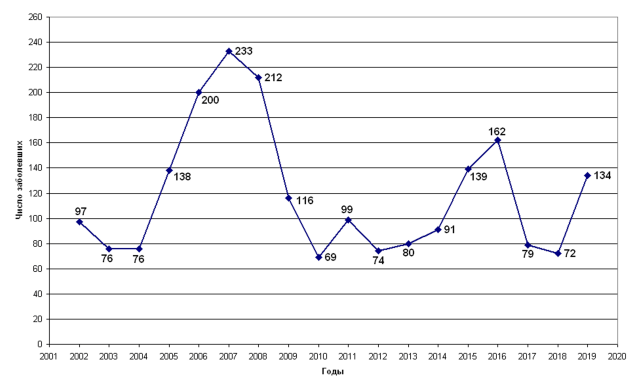

Рисунок 2. Заболеваемость крымской геморрагической лихорадкой в Российской Федерации (О санитарно-эпидемиологической обстановке в Российской Федерации... 2002-2011; О состоянии санитарно-эпидемиологического благополучия населения..., 2012-2019; Инфекционная заболеваемость в Российской Федерации за январь-декабрь, 2018 г.; Ясюкевич и др., 2016.)

Figure 2. Incidence of Crimean hemorrhagic fever in the Russian Federation (On the state of sanitary and epidemiological well-being of the population..., 2012-2019; Infectious diseases in the Russian Federation for January-December 2018 Yasyukevich et al., 2016).

На рис. 3-6 представлены модельные картографические оценки изменений нозоареала КГЛ в разные периоды XXI века в условиях умеренного сценария антропогенного воздействия на климатическую систему Земли RCP4.5.

Как следует из этих рисунков, нозоареал КГЛ в соответствии со сценарием умеренного антропогенного воздействия на климатическую систему Земли RCP4.5 в течение XXI века будет расширяться в северном направлении, а также в высокогорные районы Кавказа и Центральной Азии.

На рисунках 7 и 8 показано возможное изменение нозоареала КГЛ в соответствии со сценарием экстремального антропогенного воздействия на климатическую систему Земли RCP8.5. Как было сказано выше, картосхемы за периоды 2011-2030 гг. и 2034-2053 гг. для RCP4.5 или 2028-2047 гг. для $\mathrm{RCP} 8.5$, рассчитанные в соответствии со сценариями RCP4.5 и RCP 8.5 , отличаются лишь мелкими деталями. Поэтому рассмотрим лишь картосхемы за периоды 2041-2060 гг. и 2080-2099 гг..

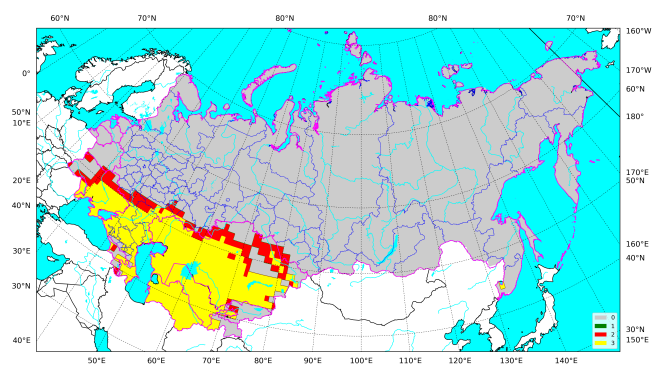

Рисунок 3. Предполагаемые изменения нозоареала КГЛ в соответствии со сценарием умеренного антропогенного воздействия на климатическую систему Земли RCP4.5 для периода (2011-2030 гг.) в сравнении с базовым периодом (1981-2000 гг.)

0 - ииркуляиия вируса отсутствует; 1 - сокращение нозоареала (в данном случае не выявлено);

2 - расширение нозоареала; 3 - ииркуляция вируса возможна в оба сравниваемых периода

Figure 3. Projected changes in the Crimean hemorrhagic fever spatial range in accordance with scenario of moderate anthropogenic impact on the Earth's climate system RCP4. 5 for the period (2011-2030) as compared to the base period (1981-2000)

0 - no virus circulation; 1 - reduction of the spatial range (not detected); 2 - expansion of the spatial range; 3 - virus circulation is possible in both periods 


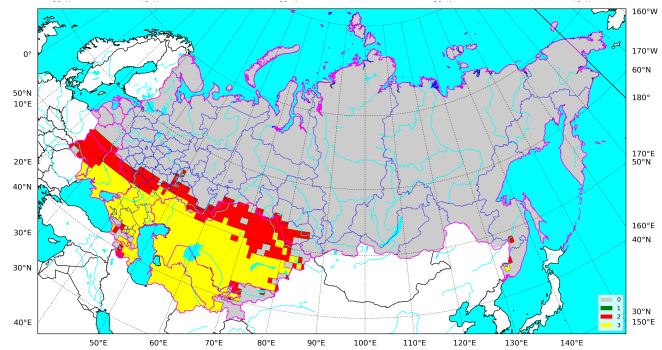

Рисунок 4. Предполагаемые изменения нозоареала КГЛ в соответствии со сценарием умеренного антропогенного воздействия на климатическую систему Земли RCP4.5 для периода (2034-2053 гг.), в сравнении с базовым периодом (1981-2000 гг.)

0 - циркуляция вируса отсутствует; 1 - сокращение нозоареала (в данном случае не выявлено);

2 - расширение нозоареала; 3 - ииркуляиия вируса возможна в оба сравниваемых периода

Figure 4. Projected changes in the Crimean hemorrhagic fever spatial range in accordance with the scenario of moderate anthropogenic impact on the Earth's climate system RCP4. 5 for the period (2034-2053) as compared to base period (1981-2000):

0 - no virus circulation; 1 - reduction of the spatial range (not detected); 2 - expansion of the spatial range; 3 - virus circulation is possible in both periods

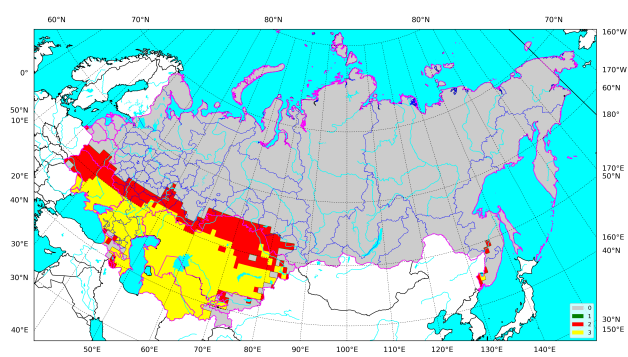

Рисунок 5. Предполагаемые изменения нозоареала КГЛ в соответствии со сценарием умеренного антропогенного воздействия на климатическую систему Земли RCP4.5 для периода (2041-2060 гг.), в сравнении с базовым периодом (1981-2000 гг.)

0 - ииркулячия вируса отсутствует; 1 - сокращение нозоареала (в данном случае не вылвлено); 2 - расширение нозоареала; 3 - циркуляиия вируса возможна в оба сравниваемых периода

Figure 5. Projected changes in the Crimean hemorrhagic fever spatial range in accordance with the scenario of moderate anthropogenic impact on the Earth's climate system RCP4. 5 for the period (2041-2060) as compared to the base period (1981-2000)

0 - no virus circulation; 1 - reduction of the spatial range

(not detected); 2 - expansion of the spatial range; 3 - virus circulation is possible in both periods

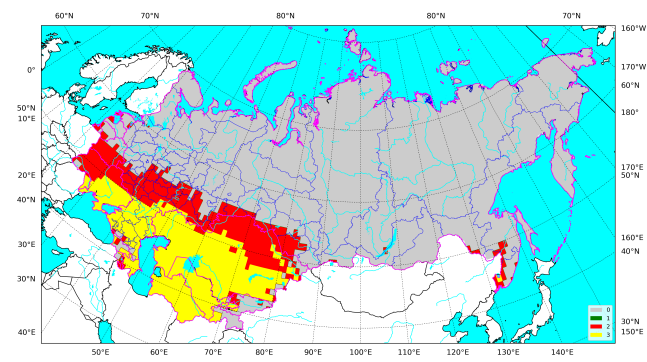

Рисунок 6. Предполагаемые изменения нозоареала КГЛ в соответствии со сценарием умеренного антропогенного воздействия на климатическую систему Земли RCP4.5 для периода (2080-2099 гг.), в сравнении с базовым периодом (1981-2000 гг.)

0 - циркуляция вируса отсутствует; 1 - сокращение нозоареала (в данном случае не выявлено); 2 - расширение нозоареала; 3 - циркуляция вируса возможна в оба сравниваемых периода

Figure 6. Projected changes in the Crimean hemorrhagic fever spatial range in accordance with the scenario of moderate anthropogenic impact on the Earth's climate system RCP4. 5 for the period (2080-2099) as compared to the base period (1981-2000)

0 - no virus circulation; 1 - reduction of the spatial range (not detected); 2 - expansion of the spatial range; 3 - virus circulation is possible in both periods 


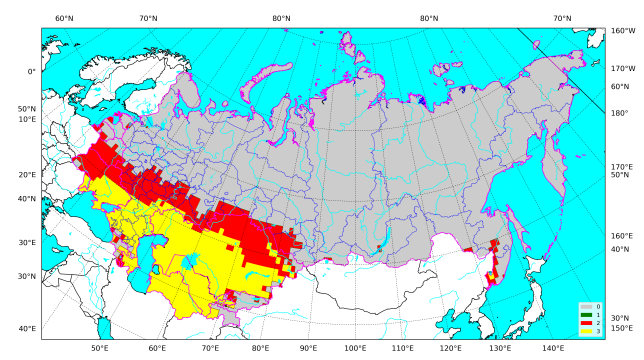

Рисунок 7. Предполагаемые изменения нозоареала КГЛ в соответствии со сценарием экстремального антропогенного воздействия на климатическую систему Земли RCP8.5 для периода (2041-2060 гг.), в сравнении с базовым периодом (1981-2000 гг.)

0 - циркуляция вируса отсутствует; 1 - сокращение нозоареала (в данном случае не выявлено);

2 - расширение нозоареала; 3 - циркулячия вируса возможна в оба сравниваемых периода

Figure 7. Projected changes in the Crimean hemorrhagic fever spatial range in accordance with the scenario of moderate anthropogenic impact on the Earth's climate system RCP8. 5 for the period (2041-2060) as compared to the base period (1981-2000)

0 - no virus circulation; 1 - reduction of the spatial range (not detected); 2 - expansion of the spatial range; 3 - virus circulation is possible in both periods

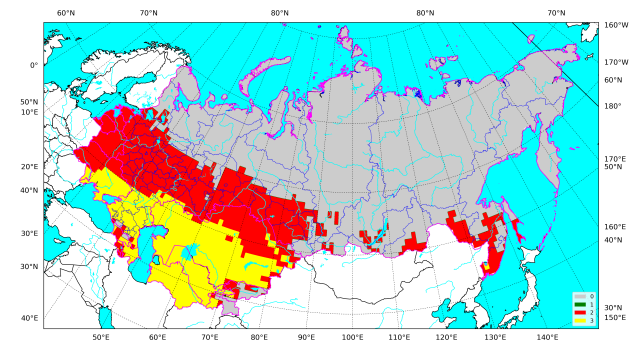

Рисунок 8. Предполагаемые изменения нозоареала КГЛ в соответствии со сценарием экстремального антропогенного воздействия на климатическую систему Земли RCP8.5 для периода (2080-2099 гг.), в сравнении с базовым периодом (1981-2000 гг.)

0 - циркуляция вируса отсутствует; 1 - сокращение нозоареала (в данном случае не выявлено);

2 - расширение нозоареала; 3 - циркуляция вируса возможна в оба сравниваемых периода

Figure 8. Projected changes in the Crimean hemorrhagic fever spatial range in accordance with the scenario of moderate anthropogenic impact on the Earth's climate system RCP8. 5 for the period (2080-2099) as compared to the base period (1981-2000)

0 - no virus circulation; 1 - reduction of the spatial range (not detected); 2 - expansion of the spatial range; 3 - virus circulation is possible in both periods

Особенности изменения нозоареала КГЛ те же, что и в соответствии со сценарием RCP4.5, но расширение нозоареала более выражено. Эти изменения наиболее полно будут реализовываться в том случае, если границы аридных зон несколько сдвинутся к северу за счет сокращения лесной зоны, что возможно и подтверждено некоторыми прогнозами (Жильцова, Анисимов, 2015).

Оценки изменений в соответствии с обоими сценариями не выявили тенденции к сокращению нозоареала.

В работе С. Е. Смирновой (2006) приводится глобальный анализ распространения геморрагической лихорадки Крым-Конго. Автор приходит к выводу, что северная граница нозоареала этого заболевания проходит в Евразии по линии Венгрия - Донецкая область - Астраханская область - озеро Балхаш по изотерме суммы эффективных температур $3000^{\circ} \mathrm{C} \cdot$ сут при пороговом значении $10^{\circ} \mathrm{C}$. Далее автор указывает, что СЭТ $=2800 \div 3000^{\circ} \mathrm{C} \cdot \mathrm{cyт}$ характерна для европейских очагов и предгорий азиатской части бывшего 
CССР, а в пустынях и полупустынях стран Центральной Азии (Таджикистан, Туркменистан, Узбекистан, Кыргызстан и Казахстан) СЭТ $=4000 \div 5860^{\circ} \mathrm{C} \cdot$ сут.

Согласно нашим оценкам (Попова и др., 2019) область, где СЭТ $\geq$ $3000^{\circ} \mathrm{C} \cdot$ сут при пороговом значении $10^{\circ} \mathrm{C}$, расположена только в южной части Республики Туркменистан по границе с Ираном и Афганистаном. Аналогичные расчеты для СЭТ $\geq 3500^{\circ} \mathrm{C} \cdot$ сут показали, что область, где было бы такое значение СЭТ, на территории бывшего СССР отсутствует. Однако, изотерма САТ $3000^{\circ} \mathrm{C} \cdot$ сут (рис. 9), учитывая существенно более мелкий масштаб рис. 10, вполне удовлетворительно совпадает с северной границей нозоареала КГЛ, приведенной в цитируемой статье. Это значение и было принято в наших модельных расчетах.

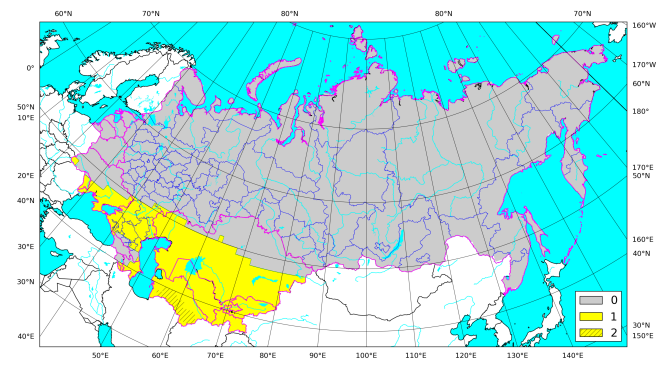

Рисунок 9. Области с суммой активных (1) и эффективных (2) температур $\geq 3000^{\circ} \mathrm{C} \cdot$ сут при пороговом значении температуры $10^{\circ} \mathrm{C} ; 0$ - сумма активных температур $<3000^{\circ} \mathrm{C} \cdot$ сут.

Figure 9. Areas where the sum of active (1) and effective (2) temperatures $\geq 3000^{\circ} \mathrm{C} \cdot$ cyT with a threshold value of temperature $10^{\circ} \mathrm{C} ; 0$ - the area where the sum of active temperatures $<3000^{\circ} \mathrm{C} \cdot{ }^{\circ}$ cyт.

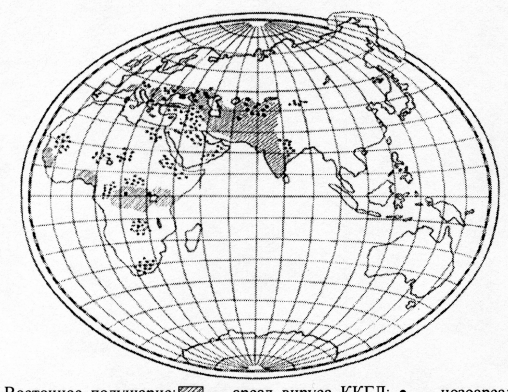

Восточное полушарие: ККГЛ (собственные данные, 1968-2000); ККГЛ по данным литературы (1970-2004)

Рисунок 10. Нозоареал КГЛ (Смирнова, 2006)

Figure 10. Crimean hemorrhagic fever spatial range (Smirnova, 2006).

\section{Заключение}

Крымская геморрагическая лихорадка (КГЛ) (геморрагическая лихорадка Крым-Конго) - острое инфекционное заболевание человека, передающееся через укусы клещей. Заболеваемость на территории Российской Федерации невелика, не более 300 случаев в год (по многолетним данным), но людей часто сопровождается тяжелым течением болезни, поражением многих органов и систем больного. 
Для моделирования границы нозоареала КГЛ был использован климатический предиктор ее распространения на территории России и соседних стран - изотерма суммы активных температур САТ $3000^{\circ} \mathrm{C} \cdot$ сут при пороге $10^{\circ} \mathrm{C}$. Она вполне удовлетворительно совпадает с северной границей нозоареала КГЛ, приведенной в специальной научной литературе. Помимо климатических ограничений нами было введено в модель и биоценологическое - северная граница лесостепи, так как переносчики - клещи аридной зоны.

Модельные картографические оценки изменений нозоареала КГЛ в соответствии со сценарием умеренного антропогенного воздействия на климатическую систему Земли RCP4.5 показали, что нозоареал КГЛ на территории России и соседних стран в течение XXI века будет расширяться в северном направлении, а также в высокогорные районы Кавказа и Центральной Азии.

Особенности изменения нозоареала КГЛ в соответствии со сценарием RCP8.5 те же, но расширение нозоареала более выражено. Эти изменения наиболее полно будут реализовываться в том случае, если граница аридных зон несколько сдвинется к северу.

Особенности изменения нозоареала КГЛ в соответствии со сценарием RCP8.5 те же, но расширение нозоареала более выражено. Эти изменения наиболее полно будут реализовываться в том случае, если северная граница аридных зон несколько сдвинутся к северу.

Оценки изменений в соответствии с обоими сценариями не выявили тенденции к сокращению нозоареала на территории России и соседних стран.

Средства специфической профилактики КГЛ (вакцинация) отсутствуют, поэтому применимы лишь средства неспецифической профилактики - уничтожение клещей на пастбищах и домашних животных, применение населением защитной одежды и репеллентов.

Ранее аналогичный результат получен нами в отношении лихорадки Западного Нила (ЛЗН) (Ясюкевич и др., 2019). Показано, что нозоареал ЛЗН предположительно будет иметь стойкую тенденцию к расширению в северном направлении. Сокращения нозоареала не ожидается. В эпидемический процесс в XXI веке будут вовлекаться все новые и новые субъекты Российской Федерации, уязвимость населения которых в отношении ЛЗН повысится. Вирус ЛНЗ выделен из большого числа переносчиков фауны России, поэтому отсутствие какого-либо из них не будет являться ограничивающим фактором. Вследствие этого при моделировании нозоареала мы не вводили биоценологических ограничений, как в случае с КГЛ, переносчиками вируса которой являются клещи аридной зоны.

Математическое моделирование ареалов возбудителей заболеваний, их переносчиков и других вредных членистоногих имеет большое значение, так как позволяет выделить регионы, где возможно их расширение и, следовательно, где произойдут негативные процессы вовлечения новых слоев населения в эпидемический процесс. 


\section{Список литературы}

Второй Оценочный Доклад Росгидромета об изменениях климата и их последствиях на территории Российской Федерации. 2014. М., Росгидромет, $1008 \mathrm{C}$.

Жильцова Е.Л., Анисимов О.А. 2015. Динамика растительности северной Евразии: анализ современных наблюдений и прогноз на 21 век. - Арктика. XXI век. Естественные науки, № 2, с. 48-59.

Инфекционная заболеваемость в Российской Федерации..., 2018. (по данным формы №1 «Сведения об инфекционных и паразитарных заболеваниях»). Роспотребнадзор: http://rospotrebnadzor.ru/activities/statistical-materials/statictic

Конго-крымская геморрагическая лихорадка. 2013. https:/www.who.int/ru/ news-room/fact-sheets/detail/crimean-congo-haemorrhagic-fever. (дата обращения 21.09.2020)

Львов Д.К., Клименко С.М., Гайдамович С.Я., Березина Л. К. и др. 1989. Арбовирусы и арбовирусные инфекции. - М., Медицина. 336 с.

О санитарно-эпидемиологической обстановке в Российской Федерации в 2002-2011: Государственный доклад. 2003-2012. -М., Федеральный центр госсанэпиднадзора Минздрава России

О состоянии санитарно-эпидемиологического благополучия населения..., 2012 - 2019. Государственный доклад. 2013-2020. -М., Федеральная служба по надзору в сфере защиты прав потребителей и благополучия человека.

Оценочный доклад об изменениях климата и их последствиях на территории Российской Федерации. Том I. Изменения климата. 2008. - М., Росгидромет, 227 с.

Попов И.О. 2016. Климатически обусловленные изменения аутэкологических ареалов иксодовых клещей Ixodes ricinus и Ixodes persulcatus на территории России и стран ближнего зарубежья. Диссертация на соискание ученой степени кандидата биологических наук. - М., ФГБОУ ВО РГАУ - МСХА им. К. А. Тимирязева, 112 с.

Попова Е.Н., Попов И.О. 2019. Моделирование потенциальных климатических ареалов биологических видов и их климатогенных изменений. - Фундаментальная и прикладная климатология, т.1, с. 58-75.

Попова Е.Н., Ясюкевич В.В., Попов И.О. 2019. Применение картографического метода для оценки различий прикладных климатических индексов САТ и СЭТ. - Проблемы экологического мониторинга и моделирования экосистем. т. 30, № 3-4, с. 11-27.

Руководство по зоонозам. 1983. /Под ред. В. И. Покровского. - Л., Медицина, $320 \mathrm{c.}$ 
Смирнова С.Е. 2006. Мировой ареал вируса крымской-конго геморрагической лихорадки. - Бюллетень сибирской медицины, Приложение 1, с. 79-87.

Тарасов В.В. 2002. Эпидемиология трансмиссивных болезней. - М., Издво МГУ, 336 с.

Ясюкевич В.В., Рыбина Е.А., Ясюкевич Н.В., Рудкова А.А. 2016. Оценки уязвимости здоровья населения Российской Федерации в отношении некоторых инфекционных и трансмиссивных заболеваний в региональном аспекте для первой половины XXI века. Проблемы экологического мониторинга и моделирования экосистем, т. 27, № 1, с. 49-73.

Ясюкевич В.В., Попов И.О., Ясюкевич Н.В. 2019. Моделирование изменений нозоареала и зоны повышенного эпидемического риска лихорадки Западного Нила на территории России в условиях ожидаемого изменения климата. Проблемы экологического мониторинга и моделирования экосистем, т. 30, № 3-4, c. 28-37. 


\title{
EXPANSION OF CLIMATIC SPATIAL RANGE OF CRIMEAN HEMORRHAGIC FEVER IN RUSSIA AND NEIGHBORING COUNTRIES UNDER PROJECTED CLIMATE CHANGE
}

\author{
V.V. Yasjukevich*, I.O.Popov** \\ Yu. A. Izrael Institute of Global Climate and Ecology, \\ 20B, Glebovskaya str., 107258 Moscow, Russia, \\ *Correspondence address:v1959@yandex.ru; igor_o_popov@mail.ru
}

\begin{abstract}
The aim of the work is to give a brief description of the Crimean hemorrhagic fever (=Crimean-Congo hemorrhagic fever) as a nosological unit and to assess possible climate-related changes in its spatial range in Russia and neighboring countries in response to projected climate change in accordance with the scenarios of moderate and extreme anthropogenic impact on the Earth's climate system RCP4.5 and RCP8.5. Crimean hemorrhagic fever is an acute infectious disease of humans transmitted through the bites of ticks of the arid zone. The incidence on the territory of the Russian Federation is low, less than 300 cases per year (according to long-term data), but in humans it is often accompanied by severe damage to many organs and systems of the patient. A climate predictor was used to model the boundary Crimean hemorrhagic fever spatial range, namely, the isotherm of the sum of active temperatures $\mathrm{SAT}=3000^{\circ} \mathrm{C}$. day at a threshold of $10^{\circ} \mathrm{C}$. It coincides quite satisfactory with the northern boundary of the Crimean hemorrhagic fever spatial range given in special scientific literature. In addition to climatic requirements, we also introduced an ecological one into the model: the northern boundary of the spatial range should be within the forest-steppe zone, since the vectors are ticks of the arid zone. Model cartographic estimates of changes in the Crimean hemorrhagic fever spatial range under scenario of moderate anthropogenic impact on the Earth's climate system RCP4.5 showed that the spatial range will expand northward, as well as into the high-altitude regions of the Caucasus and Central Asia, in the 21 st century. The features of the spatial range changes under the RCP8.5 scenario are the same, but the expansion is more pronounced. These changes will be most fully pronounced, if the arid zone border moves slightly to the North due to climate-related reduction of the forest zone. The assessment of changes under both scenarios did not revealed no a trends toward a reduction in the Crimean hemorrhagic fever spatial range in Russia and neighboring counries.
\end{abstract}

Keyword. Crimean hemorrhagic fever, climate changes, species distribution modeling, shifts in geographic ranges, climate scenarios, arid zone ticks.

\section{References}

Vtoroj ocenochnyj doklad Rosgidrometa ob izmeneniyah klimata $i$ ih posledstviyah na territorii Rossijskoj Federacii. [Rosgidromet assessment report on climate change and its consequences on the territory of the Russian Federation]. 2014. Moskwa, Rosgidromet - Moscow, Roshydromet, 1008 p. 
Zhiltsova E.L., Anisimov O.A. 2015. Dinamika rastitel'nosti severnoj evrazii: analiz sovremennyh nablyudenij i prognoz na 21 vek. [Vegetation dynamics in Northern Eurasia: analysis of current observations and forecast for the $21 \mathrm{st}$ century]. Arktika. XXI vek. Estestvennye nauki - Arctic. Twenty-first century. Natural science, no. 2, pp. 48-59.

Infekcionnaya zabolevaemost' v Rossijskoj Federacii... 2018. (po dannym formy №1 «Svedeniya ob infekcionnyh i parazitarnyh zabolevaniyah») [Infectious diseases in the Russian Federation... 2018. (according to form no 1 "information about infectious and parasitic diseases")]. Rospotrebnadzor - The CPS, http:// rospotrebnadzor.ru/activities/statistical-materials/statictic_(accessed 20.09.2020).

Kongo-krymskaya gemorragicheskaya lihoradka [Congo-Crimean hemorrhagic fever]. 2013. https://www.who.int/ru/news-room/fact-sheets/detail/crimean-congohaemorrhagic-fever, (accessed 21.09.2020)

L'vov D.K., Klimenko S.M., Gaidamovich S.Ya., Berezina L.K. et al. 1989. Arbovirusy $i$ arbovirusnye infekcii. [Arboviruses and arbovirus infections]. Moskwa, Medicina - Moscow, Medicine, $336 \mathrm{p}$.

O sanitarno-epidemiologicheskoj obstanovke v Rossijskoj Federacii v 2002-2011 godu: Gosudarstvennyj doklad. [On the sanitary and epidemiological situation in the Russian Federation in 2002-2011: State report]. 2003-2012. Moskwa: Federal'nyj centr gossanepidnadzora Minzdrava Rossii - Moscow: Federal center of state sanitary and epidemiological supervision of the Ministry of health of Russia.

O sostoyanii sanitarno-epidemiologicheskogo blagopoluchiya naseleniya $v$ Rossijskoj Federacii v 2012-2019 godu: Gosudarstvennyj doklad [On the state of sanitary and epidemiological welfare of the population in the Russian Federation in 2012- 2019: State report]. 2013-2020. Moskwa: Federal'nyj centr gigieny i epidemiologii Rospotrebnadzora - Moscow: Federal service for supervision of consumer rights protection and human welfare.

Ocenochnyj doklad ob izmeneniyah klimata $i$ ih posledstviyah na territorii Rossijskoj Federacii. 2008. Tom I. Izmeneniya klimata [Assessment report on climate change and its consequences on the territory of the Russian Federation Volume I. Climate change]. 2008. Moskwa, Rosgidromet - Moscow, Roshydromet, $227 \mathrm{p}$.

Popov I.O. 2016. Klimaticheski obuslovlennye izmeneniya autekologicheskih arealov iksodovyh kleshchej Ixodes ricinus i Ixodes persulcatus na territorii Rossii i stran blizhnego zarubezh'ya. [Climate-related changes in the outecological areas of Ixodes ricinus and Ixodes persulcatus ticks in Russia and neighboring countries]. Dissertaciya na soiskanie uchenoj stepeni kandidata biologicheskih nauk Dissertation for the degree of candidate of biological Sciences. Moscow: FGBOU VO RGAU - MSHA named after K. A. Timiryazev, 112 p.

Popova E.N., Popov I.O. 2019. Modelirovanie potencial'nyh klimaticheskih arealov biologicheskih vidov $i$ ih klimatogennyh izmenenij [Modeling of potential climatic ranges of biological species and their climate-driven changes]. 
Fundamental'naya $i$ prikladnaya klimatologiya - Fundamental And Applied Climatology. vol. 1. pp. 58-75.

Popova E.N., Yasyukevich V.V., Popov I.O. 2019. Primenenie kartograficheskogo metoda dlya ocenki razlichij prikladnyh klimaticheskih indeksov SAT i SET [Application of the cartographic method for estimating differences in the applied climate indices of SAT and SET]. Problemy ekologicheskogo monitoringa i modelirovaniya ekosistem - Problems of ecological monitoring and ecosystem modeling, vol. 30, no. 3-4, pp. 11-27.

Rukovodstvo po zoonozam [Guide to zoonoses]. 1983. Pod red. V. I. Pokrovskogo. - Ed. by V.I. Pokrovsky. Leningrad, Medicina - Leningrad, Medicine, $320 \mathrm{p}$.

Smirnova S.E. 2006. Mirovoj areal virusa krymskoj-kongo gemorragicheskoj lihoradki [World area of the Crimean-Congo hemorrhagic fever virus]. Byulleten' sibirskoj mediciny, Prilozhenie 1 - Bulletin of Siberian medicine, Appendix 1, pp. 79-87.

Tarasov V.V. 2002. Epidemiologiya transmissivnyh boleznej [Epidemiology of vector-borne diseases]. Moskwa, Izd-vo MGU - Moscow, MSU Publishing house, $336 \mathrm{p}$.

Yasyukevich V.V., Rybina E.A., Yasyukevich N.V., Rudkova A.A. 2016. Ocenki uyazvimosti zdorov'ya naseleniya Rossijskoj Federacii v otnoshenii nekotoryh infekcionnyh i transmissivnyh zabolevanij $\mathrm{v}$ regional'nom aspekte dlya pervoj poloviny XXI veka [Assessment of the vulnerability of the population of the Russian Federation to certain infectious and vector-borne diseases in the regional aspect for the first half of the XXI century]. Problemy ekologicheskogo monitoringa i modelirovaniya ekosistem - Problems of ecological monitoring and ecosystem modeling, vol. 27, no. 1, Moscow, IGKE, pp. 49-73.

Yasyukevich V.V., Popov I.O., Yasyukevich N.V. 2019. Modelirovanie izmenenij nozoareala i zony povyshennogo epidemicheskogo riska lihoradki Zapadnogo Nila na territorii Rossii v usloviyah ozhidaemogo izmeneniya klimata [Modeling of changes in the nosoareal and the zone of increased epidemic risk of West Nile fever in Russia under the conditions of expected climate change]. Problemy ekologicheskogo monitoringa i modelirovaniya ekosistem - Problems of ecological monitoring and ecosystem modeling, vol. 30, no. 3-4, pp. 28-37. 